\title{
A critical review of bi-dimensional and three- dimensional ultrasound techniques to monitor follicle growth: do they help improving IVF outcome?
}

Alberto Revelli ${ }^{1,2^{*}}$, Giorgia Martiny ${ }^{1}$, Luisa Delle Piane ${ }^{2}$, Chiara Benedetto ${ }^{1}$, Paolo Rinaudo $^{3}$ and llan Tur-Kaspa ${ }^{4}$

\begin{abstract}
Background: This review focuses on the possibility of improving the outcome of human IVF by studying the follicles where oocytes grow by ultrasound techniques. A comprehensive analysis of bi-dimensional (2D) and three-dimensional (3D) ultrasound (US) assessment of the follicle size and volume is presented.
\end{abstract}

Methods: Published reports from the year 1999 to 2014 analyzing the relationship between oocyte competence, IVF outcome and ultrasound assessment of the follicle size and volume have been critically analyzed.

Results: US assessment of growing follicles has been performed mainly by 2D-US, and while overall very useful, it has been found to be of limited usefulness in predicting oocyte competence, recognize which follicles will release a mature metaphase II oocytes and decide the ideal time to trigger ovulation. In fact, a quite wide follicle size range $(16-22 \mathrm{~mm})$ has been reported to be associated with mature oocytes with good competence toward fertilization and embryo development. It has been also shown that smaller follicles sometimes contain mature, fertilizable oocytes. However, embryos derived from smaller follicles have probably a lower implantation potential, while follicles larger than $22 \mathrm{~mm}$ often contain post-mature eggs.

Conclusions: The study of follicular size by 2D-US is of limited usefulness in helping in the identification of follicles containing the best oocytes and in choosing the best moment to trigger ovulation. Possibly the value of US in this area will be improved by large prospective studies in which automated 3D-US will be used.

Keywords: Follicle size, Follicle volume, Oocyte competence, 3D ultrasound, SonoAVC, IVF outcome

\section{Background}

Accurate follicular monitoring of Controlled Ovarian Hyperstimulation $(\mathrm{COH})$ by transvaginal ultrasound (TV-US) is considered important for the success of human in vitro fertilization (IVF). $\mathrm{COH}$, in fact, leads to the development of heterogeneous cohorts of follicles containing oocytes whose maturity and competence could be very different: it would be important to understand which follicles are developing better, with improved IVF outcomes, by using a method with low invasiveness, like TV-US.

\footnotetext{
* Correspondence: fertisave@yahoo.com

'Gynaecology and Obstetrics, Physiopathology of Reproduction and IVF Unit, Department of Surgical Sciences, University of Torino, S. Anna Hospital, Torino, Italy

${ }^{2}$ LIVET Infertility and IVF Clinic, Torino, Italy

Full list of author information is available at the end of the article
}

To date, bi-dimensional (2D) US technique has been used to monitor the ovarian response and to study the growing follicles in most of the IVF cycles performed worldwide. We analyzed the available literature of the last 15 years in order to understand if 2D-US study of the follicles in which oocytes are growing is useful for: (a) the identification of follicles containing the best oocyte, and (b) the choice of the best time to give human chorionic gonadotropin (hCG) or a gonadotropin-stimulating hormone $(\mathrm{GnRH})$-agonist bolus to trigger the final oocyte maturation before ovum pick-up (OPU).

In the 2D-transvaginal scanning, the two longest diameters of each growing follicle are measured, and the mean follicle diameter is calculated. In the last years, also threedimensional (3D) ultrasound has been tested as a tool to 
monitor $\mathrm{COH}$ during IVF, and the first data are now available.

The present review summarizes and discusses the best available evidence about how the study of follicle characteristics by US techniques may help understanding oocyte competence in order to improve IVF outcome.

\section{Methods}

We performed a computerized MEDLINE search to identify papers published until March 2014 for the relevant studies. A combination of medical subject headings and text words were used to generate two subsets of citations, one including studies on follicular diameter in IVF and intracytoplasmic sperm injection (ICSI) ('follicular size', 'follicular diameter', 'follicle volume', 'IVF' and 'ICSI') and the other including studies on oocyte competence, IVF outcomes and ultrasound assessment ('oocyte competence', 'developmental competence', 'oocyte maturation', 'IVF outcome', '2D-US', '3D-US', 'SonoAVC', 'VOCAL'). These subsets were combined using 'AND' to generate a set of citations relevant to the research question. In addition, cross-references of the selected studies were checked for other articles meeting the inclusion criteria, and if they were applicable, these studies were added to the pool of selected papers. No language restrictions were placed in any of the searches.

Studies were selected in a two-stage process. Firstly, two reviewers (LDP and GM) scrutinized the titles and abstracts from the electronic searches independently and full manuscripts of interest were obtained. Secondly, final inclusion or exclusion decisions were made on examination of the full manuscripts. In cases of duplicate publication, the most recent or complete versions were selected. Assessment of the manuscripts was performed independently by two reviewers (LDP and GM), and any disagreements about inclusion were resolved by consensus after consultation with a third reviewer (AR). Study characteristics such as number of oocytes involved, IVF/ICSI fertilization type, size categories, IVF outcomes, besides patient age and $\mathrm{COH}$ protocols for human studies and animal species for mammalian studies, were extracted from each study (Tables 1 and 2). The search for animal studies was limited only to cattle and mammalian large animals, and the exclusion criteria were the following: IVM, nuclear transfer, cloning, coculture in cumulus cells derived from large/small follicle, parthenogenetic activation, reference only to molecular findings without clinical IVF outcomes considered.

\section{Mammalian studies}

Mammalian ovaries contain a large stock of oocytes enclosed in primordial follicles. Ovarian cyclic activity induces some of these follicles to initiate growth towards a possible ovulation. However, most of these follicles terminate their growth and degenerate through atresia. In growing follicles, only a subset of oocytes are capable to support meiosis, fertilization and early embryo development to the blastocyst stage, as shown through in vitro production experiments.

An important technical details when analyzing mammalian studies is the method of assessment of follicular growth: the majority of studies but one [1] excised follicles from animals slaughtered in commercial abattoir, and later measured the diameter with caliper or eyepiece grid. Thus the context of measuring and the consequences of puncturing follicles of different dimensions are very different from in vivo infertility clinic scenario, where an ultrasound is used.

In several species, the developmental competence of the oocyte is gained progressively during late follicular growth, after the acquisition of the competence to resume and complete meiosis. Similarly to humans, the proportion of competent oocytes in animals is positively correlated to follicular diameter. Some studies defined competence as a combination of the maturity grade of the follicle (defined by the number of cells and morphological appearance of the cumulus-oocyte complex (COC)) and follicle dimensions [2-4].

Table 1 summarizes data correlating oocyte competence to follicular size in animals [1-11].

Overall animal studies mirror human data: in follicles reaching dimensions similar to those of adult follicles, IVF outcomes are shown to be comparable. Obviously, follicle diameters and their cut-offs for maturity or postmaturity are different in different animals; but, even among the same animal species, authors reported different cutoffs, as we will later show in humans (Table 2). The age of the animals is also important: follicles excised from prepubertal animals harbor a higher proportion of small follicles with an absent/reduced oocyte developmental competence $[1,11]$.

\section{D-US study of follicle size and the prediction of oocyte competence}

In literature there is general agreement with a better chance of retrieving an oocyte is present when a "large" follicle is punctured. The biological basis behind this concept is the following: a "large" follicle, more likely than a "small" one, may contain a free-floating $\mathrm{COC}$ released in the antral fluid under the influence of hyaluronic acid synthesized by cumulus cells in response to hCG [12-16]. However, there is quite a lot of confusion about the definition of ideal follicle dimension and what "large" and "small" follicle really mean. Is there a size threshold below which it is unlikely to retrieve an oocyte and/or follicles do not contain mature oocytes, and therefore their puncture is not worth unless in vitro maturation (IVM) of oocytes is available? On the opposite side, is 
Table 1 Animal studies on follicle size and IVF outcomes

\begin{tabular}{|c|c|c|c|c|c|c|c|c|}
\hline & Animal species & Oocytes & Syze $\mathrm{mm}$ & $\% \mathrm{MII}$ & $\%$ fert & $\%$ cleavage & $\begin{array}{l}\text { \% blastocyst } \\
\text { formation }\end{array}$ & $\%$ hatching \\
\hline Lonergan 1994 [5] & Bovines & 290 & 6 & n.e. & n.e. & n.e. & Increasing & n.e. \\
\hline Feng 2007 [3] & Bovines & 427 & $4-6$ & n.e. & n.e. & $\begin{array}{l}\text { Increasing from } \\
4 \mathrm{~mm} \text { onwards }\end{array}$ & Always increasing & Always increasing \\
\hline De Bem 2014 [4] & Bovines & 227 & $3-6$ & n.e. & n.e. & $\begin{array}{l}\text { Increasing from } \\
6 \mathrm{~mm} \text { onwards }\end{array}$ & $\begin{array}{l}\text { Increasing from } \\
6 \mathrm{~mm} \text { onwards }\end{array}$ & None \\
\hline Raghu 2002 [6] & Buffalos & 780 & $3-8$ & n.e. & Always increasing & Always increasing & Always increasing & n.e. \\
\hline Caixeta 2009 [7] & Buffalos & 240 & $3-6-8$ & n.e. & n.e. & n.e. & $\begin{array}{l}\text { Increasing from } \\
8 \mathrm{~mm} \text { onwards }\end{array}$ & n.e. \\
\hline Hinrichs 2000 [8] & Horses & 10753 & $6-11$ & $\begin{array}{l}\text { Always increasing } \\
\text { Together with\% of } \\
\text { condensed chromatin }\end{array}$ & n.e. & n.e. & n.e & n.e. \\
\hline Khatir 2007 [9] & Dromedaries & 399 & 6 & None & n.e. & Increasing & Increasing & $\begin{array}{l}\text { None, but any } \\
\text { pregnancy under } \\
6 \mathrm{~mm}\end{array}$ \\
\hline Crozet 1995 [2] & Goats & 543 & $3-5$ & Always increasing & n.e. & $\begin{array}{l}\text { Increasing from } \\
5 \mathrm{~mm} \text { onwards }\end{array}$ & None & n.e. \\
\hline Romaguera 2011 [1] & Goats & 313 & 3 & n.e. & n.e. & None & Increasing & None \\
\hline Marchal 2002 [10] & Pigs & 941 & $3-5$ & $\begin{array}{l}\text { Increasing from } \\
3 \mathrm{~mm} \text { onwards }\end{array}$ & $\begin{array}{l}\text { Increasing from } \\
3 \mathrm{~mm} \text { onwards }\end{array}$ & n.e. & $\begin{array}{l}\text { Increasing from } \\
3 \mathrm{~mm} \text { onwards }\end{array}$ & n.e. \\
\hline Bagg 2007 [11] & Pigs & 928 & $3-4-5$ & n.e. & n.e. & n.e. & Always increasing & n.e. \\
\hline
\end{tabular}

Only results statistically significant are reported $(p<0.05)$; all results are referred to size classes reported.

n.e. = outcome not evaluated.

none $=$ any significant difference among size classes .

always increasing = increasing from each size class onwards. 
Table 2 Human studies on follicle size and IVF outcomes

\begin{tabular}{|c|c|c|c|c|c|c|c|c|c|c|}
\hline & Study design & Age & $\mathrm{COH}$ & IVF/ICSI & Oocytes & Size mm & $\%$ MII & $\%$ fert & $\%$ cleavage & $\%$ good quality embryo \\
\hline Wittmack 1994 [13] & $\mathrm{R}$ & 23-49 & Long & Only IVF & 6879 & $\begin{array}{l}12-15-18-20- \\
21-23-24\end{array}$ & $\begin{array}{l}\text { Worst recovery rate } \\
\text { under } 12 \mathrm{~mm} \text { and } \\
\text { over } 24 \mathrm{~mm}\end{array}$ & $\begin{array}{l}\text { Increasing from } \\
12 \mathrm{~mm} \text { onwards }\end{array}$ & $\begin{array}{l}\text { Increasing from } \\
12 \mathrm{~mm} \text { onwards }\end{array}$ & None \\
\hline Inaudi 1995 [24] & $\mathrm{R}$ & $28-37$ & Short & Only IVF & 179 & $16-22$ & $\begin{array}{l}\text { None in the recovery } \\
\text { rate }\end{array}$ & n.e. & n.e. & n.e. \\
\hline Dubey 1995 [26] & R & n.e. & Long & Only IVF & 2429 & $14-16-22$ & n.e. & $\begin{array}{l}\text { Increasing from } \\
16 \mathrm{~mm} \text { onwards }\end{array}$ & n.e. & n.e. \\
\hline \multirow[t]{2}{*}{ Ectors 1997 [17] } & \multirow[t]{2}{*}{$P$} & \multirow[t]{2}{*}{ n.e. } & \multirow[t]{2}{*}{ Short } & \multirow[t]{2}{*}{ IVF/ICSI } & \multirow[t]{2}{*}{2324} & \multirow[t]{2}{*}{$16-23$} & IVF: n.e. & $\begin{array}{l}\text { IVF: increasing from } \\
16 \text { to } 23 \mathrm{~mm} \text {, later } \\
\text { decreasing }\end{array}$ & $\begin{array}{l}\text { IVF: increasing from } \\
16 \text { to } 23 \mathrm{~mm} \text {, later } \\
\text { decreasing }\end{array}$ & $\begin{array}{l}\text { IVF: increasing from } 16 \text { to } \\
23 \mathrm{~mm} \text {, later decreasing }\end{array}$ \\
\hline & & & & & & & $\begin{array}{l}\text { ICSI: increasing from } \\
16 \text { mm onwards }\end{array}$ & ICSI: none & ICSI: none & $\begin{array}{l}\text { ICSI: increasing from } \\
16 \mathrm{~mm} \text { onwards }\end{array}$ \\
\hline \multirow[t]{2}{*}{ Bergh 1998 [18] } & \multirow[t]{2}{*}{$P$} & \multirow[t]{2}{*}{33.0} & \multirow[t]{2}{*}{ Long } & \multirow[t]{2}{*}{ IVF/ICSI } & \multirow[t]{2}{*}{4159} & \multirow[t]{2}{*}{16} & \multirow[t]{2}{*}{ n.e. } & IVF: increasing & IVF: none & \multirow{2}{*}{$\begin{array}{l}\text { n.e. but increasing } \\
\text { pregnancy rate only in IVF }\end{array}$} \\
\hline & & & & & & & & ICSI: none & ICSI: none & \\
\hline Teisser 2000 [22] & $P$ & 28.0 & Long & Only IVF & 150 & 14 & Increasing & n.e. & Increasing & n.e. \\
\hline Triwitayakorn 2003 [14] & $P$ & 35.9 & Long short & Only ICSI & 991 & $10-14$ & $\begin{array}{l}\text { Always increasing } \\
\text { together with oocyte } \\
\text { recovery rate }\end{array}$ & None & n.e. & none \\
\hline \multirow[t]{2}{*}{ Rosen 2008 [19] } & \multirow[t]{2}{*}{$P$} & \multirow[t]{2}{*}{34.1} & \multirow[t]{2}{*}{ Long shortantag } & \multirow[t]{2}{*}{ IVF/ICSI } & \multirow[t]{2}{*}{2934} & \multirow[t]{2}{*}{$10-13-16-19$} & IVF: n.e. & IVF: always increasing & \multirow[t]{2}{*}{ n.e. } & IVF: always increasing \\
\hline & & & & & & & ICSI: always increasing & ICSI: always increasing & & ICSI: always increasing \\
\hline Lee 2010 [23] & $P$ & 33.5 & Long & Only ICSI & 819 & $18-20$ & $\begin{array}{l}\text { Increasing from } 18 \mathrm{~mm} \\
\text { onwards }\end{array}$ & None & None & none \\
\hline Mehri 2013 [20] & $P$ & n.e. & Long & IVF/ICSI & 360 & $15-18$ & $\begin{array}{l}\text { Increasing from } 18 \mathrm{~mm} \\
\text { onwards }\end{array}$ & $\begin{array}{l}\text { Increasing from } \\
18 \mathrm{~mm} \text { onwards }\end{array}$ & None & none \\
\hline
\end{tabular}

Only results statistically significant are reported $(p<0.05)$; all results are referred to size classes reported.

n.e. $=$ outcome not evaluated

none $=$ any significant difference among size classes .

always increasing = increasing from each size class onwards.

$\mathrm{COH}=$ controlled ovarian hyperstimulation protocol (short = short GnRH analogue, otherwise known as "flare up"; long = long GnRH analogue; antag = GnRH antagonist). 
there a size threshold above which the follicle is not worth to be punctured, especially when oocyte pick-up (OPU) could be more challenging (for example in case of ovaries located behind the uterus or pelvic varicocele), with a higher risk of intra-abdominal bleeding?

Defining a universally accepted threshold of follicle size to predict the presence of good competent oocytes is difficult. Table 2 illustrates how the available data relating oocyte maturity and follicle size are fairly inconsistent. According to some authors, oocytes are frequently found in the metaphase II (MII) mature stage when retrieved from follicles above $16 \mathrm{~mm}$ mean diameter [17], whereas a higher proportion of immature, germinal vesicle (GV) or metaphase I (MI) oocytes is found in follicles below $12 \mathrm{~mm}[12,18,19]$. Follicles above $22 \mathrm{~mm}$ often contain the so-called "post-mature" eggs, i.e. MII eggs that have undergone intra-follicular degenerative phenomena and are no more useful for fertilization [17]. Other studies put a $18 \mathrm{~mm}$ cut-off to retrieve with a better chance mature oocytes $[19,20]$. Another study [21], tough showing a clear upward trend toward yielding mature oocytes from $16 \mathrm{~mm}$ follicles onward (approximately corresponding to a $2 \mathrm{ml}$ volume), also reported that follicles from 11 to $15 \mathrm{~mm}$ sometimes can harbour mature oocytes. Other authors [22,23] confirmed that follicles below $14 \mathrm{~mm}$ diameter seldom contain MII oocytes, both in normal and polycystic (PCO) ovaries. Overall there is evidence that follicles having a mean diameter between 16 and $22 \mathrm{~mm}$ are those with the highest likelihood of containing MII oocytes, but even small follicles can occasionally generate MII oocytes [24].

\section{May 2D-US imaging predict oocyte competence toward fertilization and embryo development?}

Follicle number and size were reported to be independent predictors of likelihood of fertilization, morphological quality and number of embryos [25]. In a large retrospective study considering 2429 oocytes from 215 patients, follicular size above $16 \mathrm{~mm}$ at OPU was the best single indicator of oocyte fertilization potential, superior to the morphological characterization of the cumulus-oocyte complex [26]. Another study showed that fertilization and implantation rates with a leading follicle of $20 \mathrm{~mm}$ are higher than with a leading follicle of smaller size [27]. One of the largest studies, including 2934 oocytes, reported that oocytes with the best chance of fertilization are those from follicles above $18 \mathrm{~mm}$, while the odd of retrieving MII oocytes and of fertilization progressively declines diminishing the follicle size [19]. Conversely, the rate of polispermy with conventional IVF was higher in follicles of smaller size, and embryos obtained from smaller follicles had a significantly higher fragmentation rate compared with those derived from eggs retrieved in bigger follicles [19]; these effects are likely due to a reduced oocyte competence, to either safeguard from more than one sperm getting in and to develop properly during first cleavage steps.

However, in none except two $[17,19]$ of these studies it was possible to identify a clear relationship between follicle size and morphological quality of the in vitro produced embryos. Possibly follicles between 16 and $22 \mathrm{~mm}$ contain oocytes of comparable quality, which finally leads to embryos of similar morphological score.

The next key question is: can follicular size be predictive of pregnancy? A retrospective study on 200 IVF cycles found that follicle size at OPU and follicular fluid volume were two of the only 4 parameters which resulted predictive of the take-home baby rate, among 53 examined [28]. Some authors reported that although oocytes from small follicles are sometimes found to be mature and yield fertilization, the resulting pregnancy rates are significantly lower compared to oocytes from follicles above $16 \mathrm{~mm}$ [18]. This finding suggests that even if meiotically mature, oocytes from smaller follicles could be defective in specific cellular events involving cytoskeletal organization and thus later affecting cytoplasmic maturation [29]. Contrasting observations, however, are reported: a large prospective study including 9933 follicles from 535 IVF cycles observed that oocytes from small follicles (12 mm or less) rarely get fertilized, but, once fertilized, they lead to apparently good quality embryos [30]. Similarly, when embryos obtained from oocytes originating from smaller follicles are transferred, the pregnancy rate is similar to the one observed with embryos derived from oocytes of larger follicles [31].

\section{Why data linking oocyte competence and size of the follicle are overall so inconsistent?}

Conflicting results found in the published reports are likely due to several reasons including study design: some studies have a limited number of patients and/or are based on retrospective observations. There are also merely technical reasons: the evaluation of oocyte maturity at the stereomicroscope, usually performed soon after oocyte retrieval, may be misleading as some oocytes that immediately appear as MII could still be in the telophase of the first meiotic division. This "morphological artifact" may have induced some authors to overestimate the rate of maturity when oocytes retrieved from small follicles were considered. Secondly, often different methods to determine follicular dimensions are adopted: either the follicular fluid volume collected at OPU is used to estimate follicular volume, or follicle dimensions are measured by US just prior to oocyte puncture. The methodology used in different studies is important to know, since follicles have a median growth of approximately $2 \mathrm{~mm}$ from the day of ovulation triggering to the day of OPU [20]. 
Though any of the above-mentioned studies reported separated data according to $\mathrm{COH}$ protocols, also the type of ovarian stimulation is likely to affect the genetic and/or biochemical intra-follicular environment. As a consequence, different medications and/or protocols could influence the size at which follicles contain competent oocytes. For example, when clomiphene citrate (CC) is employed in $\mathrm{COH}$, alone [32] or added to gonadotropins [33], oocytes from follicles $<18 /<20 \mathrm{~mm}$ show significantly lower fertilization potential than oocytes derived from larger follicles. Possibly when the pituitary secretion of endogenous gonadotropins is stimulated (with the use of clomiphene citrate), the follicle size at which the eggs reach optimal competence is higher than observed when a direct ovarian stimulation with exogenous gonadotropins is used. It was also reported that when GnRH-antagonists are used (and thus the first week of follicle growth occurs without pituitary block, with the contribute of endogenous gonadotropins), oocyte maturation is obtained at a lower follicle size than when a GnRH-agonist is given in the classical "long" protocol (and the pituitary block precedes $\mathrm{COH}$ ) [34]. Another possible bias among studies could be the fertilization type involved. Some authors reported separately results from IVF and ICSI cycles [17-19] and usually ICSI seems to be less affected from different follicle sizes.

Interestingly, none of the studies reported any correlation between IVF outcomes, follicular diameters and age of the patients enrolled. Overall, in many studies the average age is approximately $34-35$ years old, but with a 4 to 5 years of standard deviation: this extends the age of the patient population to a large range, from before thirties until early forties when IVF outcomes could be very different. Further, any study correlate follicular size to days of stimulation needed to reach maturity, while this parameter could be easily recorded and maybe correlate to female age and recovery rate of MII oocytes.

Even intrinsic defects of 2D-US technique may contribute to generate contrasting data: for example lack of standardization of US measurement among members of the team or the use of different ultrasound scanners and settings may lead to different results. The manual 2D-US monitoring of follicular growth, in fact, has important limitations when many follicles are simultaneously growing in each ovary. 2D-US imaging, in fact, makes assumption that an object has a regular shape and uses the measurement of two axis as surrogates to estimate its true size: this may be inaccurate for follicles having uneven and irregular shapes, like those developing during $\mathrm{COH}$. Furthermore, accurate follicles measurement could be even more difficult to perform in the presence of anatomical alteration. Indeed, endometriomas are frequently detected in an infertile population, and it was reported that both ovarian-volume measurement and antral follicle count lose accuracy in the presence of ovarian cysts as well as in the presence of a corpus luteum $[35,36]$.

Finally, measuring the mean diameter of multiple follicles is time-consuming, and may result in crowded waiting rooms and frustrated patients; this forces the doctor to work quickly and, probably, with less precision. The final result is an intra- and inter-observer variation that has been estimated to be around $20 \%$ when several follicles are contemporaneously present inside the ovaries [37].

\section{D-US study of follicle volume and the prediction of oocyte competence}

A new opportunity to get useful insights about our topic could be presently offered by the 3D-US scanning. Currently 3D-US may be performed by manual measurement of follicle circumference through Virtual Organ Computer-Aided Analysis (VOCAL) or by an automated US application, the Sonography-based Automated Volume Calculation (SonoAVC) [38,39].

Manual measurement and SonoAVC correlate quite well in the assessment of follicle morphology [40,41], but SonoAVC has a higher intra- and inter-observer reproducibility than VOCAL [42], and can also be used interchangeably together with conventional $2 \mathrm{D}$ measurement [43-45].

SonoAVC automatically identifies the boundaries of follicles and provides an estimate of their largest diameters in three orthogonal planes [38]. This technology implies 3D image manipulation and post-processing [46]. Each individual follicle is identified on the screen with a specific color and later shown together with all other follicles, with dimensions and relative sizes calculated using the relaxed sphere technique. The volume calculation is based on voxel count within the identified hyper-echoic structure and finally represents a true measure of follicular volume regardless of the regularity of its shape [47,48]. This is a large improvement versus conventional 2D-US: in fact, when the measured follicle is other than spherical, evaluation of the mean follicular diameter risks to be an overestimate and it is a matter of fact that ovaries under $\mathrm{COH}$ predominantly harbor ellipsoid follicles [21].

Both VOCAL and SonoAVC provide an accurate way to measure ovarian follicle volume: a $95 \%$ correspondence between their measurement and the actual follicle volume (obtained by measuring the volume of the aspirated follicular fluid) was reported $[42,47,48]$. Deutch [40], showed $<0.02 \mathrm{ml}$ error comparing spheres of known volume with a hyper-echoic matrix using an ultrasound phantom. Rousian [49], who used spheres having larger volume than the previous study, showed that the SonoAVC system slightly underestimates the volume (by a mean difference of $-0.63 \mathrm{ml}$ ). 
The advantage of SonoAVC over 2D-US may be the possibility of getting follicle measurement automatically and consequently more quickly - and with a very low inter-observer variability, overcoming the lack of standardization in US technique that represents an important limitation of 2D-US. SonoAVC also allows to virtually repeat US examination in the absence of the patient: this appears to be useful both for training resident doctors and to be used as a method of quality control and standardization of the technique.

Some limitations are also present using 3D-US methods: the ultrasound machines are highly costly and this could limit affordability for smaller infertility centers; furthermore 3D machine still need to rely on 2D-scan when good quality images cannot be recorded [50].

To date, only few studies evaluated the use of SonoAVC for monitoring follicular growth in stimulated ovaries. A very good correspondence between $2 \mathrm{D}$ and SonoAVC measurements of follicle size was reported, and SonoAVC was found to significantly reduce the time needed to perform US examination [38,40,43,48,50,51]. Of notice is that the reduced time reported for SonoAVC is the comprehensive time for both volume acquisition, post processing when needed and data analysis. Unfortunately, none of the studies performed to date was aimed at testing how the 3D-US technique could elicit any improvement in IVF success rate [42,52]; in fact, in these studies, hCG ovulation trigger injection was administered as usual (according to the mean diameter of the leading follicle) and not looking at its 3D-measured volume. The only study comparing results between women monitored with either 2D-US and SonoAVC reported similar number of mature oocytes retrieved, fertilization and clinical pregnancy rates [51].

Anytime a new tool is introduced, we first collect conflicting reports. In the past, for example, when vascularity assessment was performed, only some authors correlated IVF outcome to power Doppler parameters [25,53,54]; thus suggesting the need to standardize the technique and to integrate it with standard 2D-US, before introduction in the clinical practice. Similarly, though reassuring reports on 3D-US previously reported, there is still the need to perform new studies on follicular volume calculation as a new criterion to decide when ovulation trigger should be performed.

\section{Conclusions}

The morphological study of the follicle size using 2D-US equipment is routinely performed in IVF Units worldwide, and its tolerability, real time results renders it, in theory, the ideal tool to get useful indications about oocyte competence. Unfortunately, the available evidence fails to clearly indicate a size range within which follicles contain oocytes of good quality, and gives just approximate ideas. Mature, competent oocytes are more likely to derive from follicles that have a mean diameter between 16 and $22 \mathrm{~mm}$ when their final maturation is triggered. Fertilizable oocytes may sometimes be retrieved from smaller follicles both in women with normal or polycystic ovaries, but the derived embryos are suspected to have a reduced implantation potential than those originated from eggs contained in follicles within the above mentioned size range.

The available data about oocyte competence and follicle size, however, are quite inconsistent because of the small size and retrospective nature of most studies, for possible "biological artifacts" in assessing oocyte maturity, as well as for the intrinsic limitations of the 2D-US technique. As a consequence, at present we cannot make a clear distinction on when to trigger ovulation or wait, and on which follicle to aspirate or not on the basis of its US characteristics.

Better knowledge in this area could be helpful to optimize IVF outcome by refining $\mathrm{COH}$ protocols and obtain high quality oocytes. It is questionable but possible that prospective studies performed using 3D automated US machines, either alone or with Doppler evaluation, will be able to standardize follicle assessment and reduce the intra- and inter-observer variability.

\section{Competing interests}

The authors declare that they have no competing interests.

\section{Authors' contributions}

AR, GM, LDP and PR performed the reference search, analyzed the available literature and wrote the manuscript. CB and IT critically reviewed the manuscript and helped to draft the final version. PR provided an accurate language revision of the paper. All authors approved the final manuscript.

\section{Author details}

'Gynaecology and Obstetrics, Physiopathology of Reproduction and IVF Unit, Department of Surgical Sciences, University of Torino, S. Anna Hospital, Torino, Italy. ${ }^{2}$ LIVET Infertility and IVF Clinic, Torino, Italy. ${ }^{3}$ Department of Obstetrics, Gynaecology, and Reproductive Sciences, University of California San Francisco, San Francisco, CA, USA. ${ }^{4}$ Institute for Human Reproduction (IHR) and the Department of Obstetrics and Gynecology, University of Chicago, Chicago, IL, USA.

Received: 14 April 2014 Accepted: 1 September 2014

Published: 24 November 2014

\section{References}

1. Romaguera R, Moll X, Morató R, Roura M, Palomo MJ, Catalá MG, JiménezMacedo AR, Hammami S, Izquierdo D, Mogas T, Paramio MT: Prepubertal goat oocytes from large follicles result in similar blastocyst production and embryo ploidy than those from adult goats. Theriogenology 2011, 76:1-11

2. Crozet N, Ahmed-Ali M, Dubos MP: Developmental competence of goat oocytes from follicles of different size categories following maturation, fertilization and culture in vitro. J Reprod Fertil 1995, 103:293-298.

3. Feng WG, Sui HS, Han ZB, Chang ZL, Zhou P, Liu DJ, Bao S, Tan JH: Effects of follicular atresia and size on the developmental competence of bovine oocytes: a study using the well-in-drop culture system. Theriogenology 2007, 67:1339-1350.

4. De Bem T, Adona P, Bressan F, Mesquita L, Chiaratti M, Meirelles F, Leal C: The influence of morphology, follicle size and $\mathrm{BCl}-2$ and Bax transcripts on the developmental competence of bovine oocytes. Reprod Domest Anim. in press. 
5. Lonergan P, Monaghan P, Rizos D, Boland MP, Gordon I: Effect of follicle size on bovine oocyte quality and developmental competence following maturation, fertilization, and culture in vitro. Mol Reprod Dev 1994 37:48-53.

6. Raghu HM, Nandi S, Reddy SM: Follicle size and oocyte diameter in relation to developmental competence of buffalo oocytes in vitro. Reprod Fertil Dev 2002, 14:55-61.

7. Caixeta ES, Ripamonte P, Franco MM, Junior JB, Dode MA: Effect of follicle size on mRNA expression in cumulus cells and oocytes of Bos indicus: an approach to identify marker genes for developmental competence. Reprod Fertil Dev 2009, 21:655-664.

8. Hinrichs K, Schmidt AL: Meiotic competence in horse oocytes: interactions among chromatin configuration, follicle size, cumulus morphology, and season. Biol Reprod 2000, 62:1402-1408.

9. Khatir $\mathrm{H}$, Anouassi A, Tibary A: Effect of follicular size on in vitro developmental competence of oocytes and viability of embryos after transfer in the dromedary (Camelus dromedarius). Anim Reprod Sci 2007 99:413-420

10. Marchal R, Vigneron C, Perreau C, Bali-Papp A, Mermillod P: Effect of follicular size on meiotic and developmental competence of porcine oocytes. Theriogenology 2002, 57:1523-1532.

11. Bagg MA, Nottle MB, Armstrong DT, Grupen CG: Relationship between follicle size and oocyte developmental competence in prepubertal and adult pigs. Reprod Fertil Dev 2007, 19:797-803.

12. Scott RT, Hofmann GE, Muasher SJ, Acosta AA, Kreiner DK, Rosenwaks Z: Correlation of follicular diameter with oocyte recovery and maturity at the time of transvaginal follicular aspiration. $J$ in Vitro Fertil Embryo Transf $1989,6: 73-75$

13. Wittmaack FM, Kreger DO, Blasco L, Turek RW, Mastroianni L Jr, Lessey BA: Effect of follicular size on oocyte retrieval, fertilization, cleavage, and embryo quality in in vitro fertilization cycles: a 6-year data collection. Fertil Steril 1994, 62:1205-1210.

14. Triwitayakorn A, Suwajanakorn S, Pruksananonda K, Sereepapong W, Ahnonkitpanit V: Correlation between human follicular diameter and oocyte outcomes in an ICSI program. J Assist Reprod Genet 2003, 20:143-147.

15. Suchanek E, Simunic V, Juretic D, Grizelj V: Follicular fluid contents of hyaluronic acid, follicle-stimulating hormone and steroids relative to the success of in vitro fertilization of human oocytes. Fertil Steril 1994, 62:347-352.

16. Oktay K, Briggs D, Gosden RG: Ontogeny of follicle-stimulating hormone receptor gene expression in isolated human ovarian follicles. J Clin Endocrinol Metab 1997, 82:3748-3751.

17. Ectors FJ, Vanderzwalmen P, Van Hoeck J, Nijs M, Verhaegen G, Delvigne A Schoysman R, Leroy F: Relationship of human follicular diameter with oocyte fertilization and development after in-vitro fertilization or intracytoplasmic sperm injection. Hum Reprod 1997, 12:2002-2005.

18. Bergh C, Broden H, Lundin K, Hamberger L: Comparison of fertilization, cleavage and pregnancy rates of oocytes from large and small follicles. Hum Reprod 1998, 13:1912-1915.

19. Rosen MP, Shen S, Dobson AT, Rinaudo PF, McCulloch CE, Cedars MI: A quantitative assessment of follicle size on oocyte developmental competence. Fertil Steril 2008, 90:684-690.

20. Mehri S, Levi Setti PE, Greco K, Sakkas D, Martinez G, Patrizio P: Correlation between follicular diameters and flushing versus no flushing on oocyte maturity, fertilization rate and embryo quality. J Assist Reprod Genet 2014 31:73-77.

21. Shmorgun D, Hughes E, Mohide P, Roberts R: Prospective cohort study of three- versus two-dimensional ultrasound for prediction of oocyte maturity. Fertil Steril 2010, 93:1333-1337.

22. Teissier MP, Chable H, Paulhac S, Aubard Y: Comparison of follicle steroidogenesis from normal and polycystic ovaries in women undergoing IVF: relationship between steroid concentrations, follicle size, oocyte quality and fecundability. Hum Reprod 2000, 15:2471-2477.

23. Lee TF, Lee RK, Hwu YM, Chih YF, Tsai YC, Su JT: Relationship of follicular size to the development of intracytoplasmic sperm injection-derived human embryos. Taiwan J Obstet Gynecol 2010, 49:302-305.

24. Inaudi P, Germond M, Senn A, De Grandi P: Timing of hCG administration in cycles stimulated for in vitro fertilization: specific impact of heterogeneous follicle sizes and steroid concentrations in plasma and follicle fluid on decision procedures. Gynecol Endocrinol 1995, 9:201-208.
25. Merce' LT, Bau S, Barco MJ, Troyano J, Gay R, Sotos F, Villa A: Assessment of the ovarian volume, number and volume of follicles and ovarian vascularity by three-dimensional ultrasonography and power Doppler angiography on the HCG day to predict the outcome in IVF/ICSI cycles. Hum Reprod 2006, 21:1218-1226.

26. Dubey AK, Wang HA, Duffy P, Penzias AS: The correlation between follicular measurements, oocyte morphology, and fertilization rates in an in vitro fertilization program. Fertil Steril 1995, 64:787-790.

27. Miller KF, Goldberg JM, Falcone T: Follicle size and implantation of embryos from in vitro fertilization. Obstet Gynecol 1996, 88:583-586.

28. Saith RR, Srinivasan A, Michie D, Sargent IL: Relationships between the developmental potential of human in-vitro fertilization embryos and features describing the embryo, oocyte and follicle. Hum Reprod Update 1998, 4:121-134.

29. Katz N, Tur-Kaspa I: Cytoplasmic maturity of metaphase II human oocytes: biologic importance and clinical implication for in vitro fertilization. Reprod Technol 2000, 10:170-173.

30. Salha O, Nugent D, Dada T, Kaufmann S, Levett S, Jenner L, Lui S, Sharma V: The relationship between follicular fluid aspirate volume and oocyte maturity in in-vitro fertilization cycles. Hum Reprod 1998, 13:1901-1906.

31. Nagai S, Yasumizu T, Kasai T, Hirata S, Mizuno K, Kato J: Effect of oocyte retrieval from a small leading follicle in fixed-schedule in vitro fertilization program. J Obstet Gynaecol Res 1997, 23:165-169.

32. Quigley MM, Wolf DP, Maklad NF, Dandekar PV, Sokoloski JE: Follicular size and number in human in vitro fertilization. Fertil Steril 1982, 38:678-681.

33. Nataprawira DS, Harada T, Sekijima A, Mio Y, Terakawa N: Assessment of follicular maturity by follicular diameter and fluid volume in a program of in vitro fertilization and embryo transfer. Asia Oceania J Obstet Gynaecol 1992, 18:225-230.

34. Nogueira D, Friedler S, Schachter M, Raziel A, Ron-El R, Smitz J: Oocyte maturity and preimplantation development in relation to follicle diameter in gonadotropin-releasing hormone agonist or antagonist treatments. Fertil Steril 2006, 85:578-583.

35. Broekmans FJ, Kwee J, Hendriks DJ, Mol BW, Lambalk CB: A systematic review of tests predicting ovarian reserve and IVF outcome. Hum Reprod Update 2006, 12:685-718.

36. Hendriks DJ, Kwee J, Mol BW, te Velde ER, Broekmans FJ: Ultrasonography as a tool for the prediction of outcome in IVF patients: a comparative meta-analysis of ovarian volume and antral follicle count. Fertil Steril 2007, 87:764-774

37. Deutch TD, Abuhamad AZ, Matson DO, Bocca S, Stadtmauer LA, Oehningr SC: Automated calculation of ovarian follicular diameters using three dimensional sonography in women undergoing in vitro fertilization (IVF): a prospective evaluation of a novel software. Fertil Steril 2007, 88:580

38. Ata B, Tulandi $\mathrm{T}$ : Ultrasound automated volume calculation in reproduction and in pregnancy. Fertil Steril 2011, 95:2163-2170.

39. Tur-Kaspa I, Stadtmauer L: Ultrasonography in Assisted Reproduction. In Textbook of Assisted Reproductive Techniques: Laboratory and Clinical Perspectives. Edited by Gardner DK, Weissman A, Howles CM, Shoam Z 2004.

40. Deutch TD, Joergner I, Matson DO, Oehninger S, Bocca S, Hoenigmann D, Abuhamad A: Automated assessment of ovarian follicles using a novel three-dimensional ultrasound software. Fertil Steril 2009, 92:1562-1568.

41. Raine-Fenning N, Jayaprakasan K, Deb S, Clewes J, Joergner I, Dehghani Bonaki S, Johnson I: Automated follicle tracking improves measurement reliability in patients undergoing ovarian stimulation. Reprod Biomed Online 2009, 18:658-663.

42. Salama S, Arbo E, Lamazou F, Levailllant JM, Frydman R, Fanchin R: Reproducibility and reliability of automated volumetric measurement of single preovulatory follicles using SonoAVC. Fertil Steril 2010, 93:2069-2073

43. Deb S, Campbell BK, Clewes JS, Raine-Fenning NJ: Quantitative analysis of antral follicle number and size: a comparison of two-dimensional and automated three-dimensional ultrasound techniques. Ultrasound Obstet Gynecol 2010, 35:354-360.

44. Deb S, Kannamannadiar J, Campbell BK, Clewes JS, Raine-Fenning NJ: The inter-ovarian variation in three-dimensional ultrasound markers of ovarian reserve in women undergoing baseline investigation for subfertility. Fertil Steril 2011, 95:667-672.

45. Ata B, Seyhan A, Reinblatt SL, Shalom-Paz E, Krishnamurthy S, Tan SL Comparison of automated and manual follicle monitoring in an 
unrestricted population of 100 women undergoing controlled ovarian stimulation for IVF. Hum Reprod 2011, 26:127-133.

46. Deb S, Jayaprakasan K, Campbell BK, Clewes JS, Johnson IR, Raine-Fenning $\mathrm{NJ}$ : The intra-observer and inter-observer reliability of automated antral follicle counts made using three-dimensional ultrasound and Sono-AVC. Ultrasound Obstet Gynecol 2009, 33:477-483.

47. Raine-Fenning N, Jayaprakasan K, Clewes J, Joergner I, Bonaki SD, Chamberlain S: SonoAVC: a novel method of automatic volume calculation. Ultrasound Obstet Gynecol 2008, 31:691-696.

48. Raine-Fenning N, Jayaprakasan K, Chamberlain S, Devlin L, Priddle H, Johnson I: Automated measurements of follicle diameter: a chance to standardize? Fertil Steril 2009, 91:1469-1472.

49. Rousian M, Verwoerd-Dikkeboom CM, Koning AH, Hop WC, van der Spek PJ, Exalto $\mathrm{N}$ : Early pregnancy volume measurements: validation of ultrasound techniques and new perspectives. Br J Obstet Gynaecol 2009, 116:278-285.

50. Rodríquez-Fuentes A, Hernández J, García-Guzman R, Chinea E, laconianni L, Palumbo A: Prospective evaluation of automated follicle monitoring in 58 in vitro fertilization cycles: follicular volume as a new indicator of oocyte maturity. Fertil Steril 2010, 93:616-620.

51. Raine-Fenning N, Deb S, Jayaprakasan K, Clewes J, Hopkisson J, Campbell B: Timing of oocyte maturation and egg collection during controlled ovarian stimulation: a randomized controlled trial evaluating manual and automated measurements of follicle diameter. Fertil Steril 2010, 94:184-188.

52. Lamazou F, Arbo E, Salama S, Grynberg M, Frydman R, Fanchin R: Reliability of automated volumetric measurement of multiple growing follicles in controlled ovarian hyperstimulation. Fertil Steril 2010, 94:2172-2177.

53. Shrestha SM, Costello MF, Sjoblom P, McNally G, Bennett M, Steigrad SJ, Hughes GJ: Power Doppler ultrasound assessment of follicular vascularity in the eraly follicular phase and its relationship with outcome of in vitro fertilization. J Assist Reprod Genet 2006, 23:161-169.

54. Ragni G, Anselmino M, Nicolosi AE, Brambilla ME, Calanna G, Somigliana E: Follicular vascularity is not predictive of pregnancy outcome in mild controlled ovarian stimulation and IUI cycles. Hum Reprod 2007, 22:210-214

doi:10.1186/1477-7827-12-107

Cite this article as: Revelli et al:: A critical review of bi-dimensional and three-dimensional ultrasound techniques to monitor follicle growth: do they help improving IVF outcome? Reproductive Biology and Endocrinology 2014 12:107.

\section{Submit your next manuscript to BioMed Central and take full advantage of:}

- Convenient online submission

- Thorough peer review

- No space constraints or color figure charges

- Immediate publication on acceptance

- Inclusion in PubMed, CAS, Scopus and Google Scholar

- Research which is freely available for redistribution 